\title{
What Shall we do with the Drunken Sailor? Product Safety in the Aftermath of $3 D$ Printing
}

\author{
Klaus HEINE* and Shu LI**
}

\begin{abstract}
This article contributes to the discussion about proper product safety in the wake of disruptive digital technologies. By picking the example of $3 D$ printing we analyse why incumbent product liability law does not incentivise optimal deterrence of harmful $3 D$ printed products. We identify the new business models associated with $3 D$ printing as the main trigger for the non-applicability of incumbent liability law. The new business models are characterised by making no strong reference to economies of scale. As a result, the informational content of specific producers and their products is scarce and the identification of tortfeasors becomes a challenge for the legal system. While there is yet no easy solution to the problem, we provide at the end of the article an inventory of institutions that may take the lead in finding new proper liability rules and safety regulations.
\end{abstract}

\section{INTRODUCTION}

The aim of any liability regime is twofold: (1) in the event of an accident the victim shall receive fair compensation; and (2) the liability regime shall allocate responsibilities along the value chain from the producer towards the consumer. ${ }^{1}$ The producers and consumers shall be incentivised to take due care, thereby implementing the optimal care level. Under ideal circumstances a liability regime leads to optimal deterrence of producing or selling defective products. Hence, the socially optimal amount of defective products will be sold. ${ }^{2}$

While liability regimes around the world may differ in detail, it is safe to say that they have always adapted to the technical givens and societal circumstances relevant at a specific moment in time. ${ }^{3}$ Over the last hundred years we see as a general pattern that mass manufacturing led first to the legal innovation of organisational liability and later to mass torts in which whole industries became liable (eg asbestos cases). ${ }^{4}$ Moreover, in

\footnotetext{
* Jean Monnet Chair of Economic Analysis of European Law at the Erasmus School of Law, Erasmus University Rotterdam, email: heine@law.eur.nl.

** PhD candidate at Erasmus School of Law, Erasmus University Rotterdam, email: li@law.eur.nl.

1 G Calabresi, The Costs of Accidents (Yale University Press 1970) 24-35.

2 T Miceli, The Economic Approach to Law (Stanford University Press 2004) 85.

3 M Reimann, "Liability for Defective Products at the Beginning of the Twenty-First Century: Emergence of a Worldwide Standard?" (2003) 51 American Journal of Comparative Law 751.

4 M Whincup, "Product Liability Laws in Common Market Countries" (1982) 19 Common Market Law Review 521; see also G Howells, "Product Liability - A History of Harmonisation" in D Fairgrieve (ed), Product Liability in Comparative Perspective (Cambridge University Press 2005) 202.
} 
the European Union the Product Liability Directive from 1985 accomplished not only the protection of consumers to a high standard, but the Directive also helped to fulfil the Single Market by creating a level playing field and the enforcement of fair competition. ${ }^{5}$

In the past the developments in liability law were challenging mainly from a doctrinal legal point of view. The single developments built upon each other and could rely on an analytical framework in which it was clear who the producers and who the consumers were. ${ }^{6}$ There was also certainty about the properties of the production technology (value chain) and whom to hold responsible in case of wrongdoing. This is also true for the economic analysis of tort law, which requires for an optimal allocation of liability that the single steps in a value chain can be identified and the decision makers at each step in the value chain can be incentivised accordingly.

However, the clear definition of value chains is no longer the case in a world of big data, artificial intelligence and $3 \mathrm{D}$ printers. ${ }^{7}$ The new technologies create legal disruptions which make it necessary that jurisdictions reconsider their liability regimes and replace (if necessary) incumbent laws, regulations and procedures.

$3 \mathrm{D}$ printing technology is a disruptive technology that produces an object layer by layer instructed by a digital file (ie the CAD file). ${ }^{8}$ 3D printing was invented in the $1980 \mathrm{~s}$, but only in recent years has it been - due to powerful ICT infrastructures - embraced by professional and occasional users. 3D printing has been successfully applied in industrial manufacturing (eg tailor-made ship propellers), medicine (eg artificial hip joints and tissue), toys (eg LEGO bricks), household replacement parts and food (eg pizza) to name only a few applications. In parallel with the technological development and diffusion of 3D printing, specific business models of 3D printing became established. Various electronic platforms give users the access to CAD files ${ }^{9}$ as well as $3 \mathrm{D}$ printers ${ }^{10}$ around the world. While this new technology opens the door to new advanced products with sheer unlimited local availability, it also creates risks and possible harm for users and consumers.

In the following we will highlight the principal challenges that unfold through digitisation for liability regimes in the case of $3 \mathrm{D}$ printing. The case of $3 \mathrm{D}$ printing is iconic for a better understanding of how far new technologies disrupt our traditional understanding of applying liability law. Our main focus will be on the argument that in the digital world value chains are no longer linear, and as a consequence the informational content associated with a specific step in the value chain becomes blurred. This leads ultimately to a failure when targeting potential wrongdoers. At the end of our

\footnotetext{
5 Recital 1 of Council Directive 85/374/EEC of 25 July 1985 on the approximation of the laws, regulations and administrative provisions of the Member States concerning liability for defective products [1985] OJ L 210.

6 G Ritzer and N Jurgenson, "Production, Consumption, Prosumption: The Nature of Capitalism in the Age of the Digital 'Prosumer"' (2010) 10(1) Journal of Consumer Culture 13.

7 M Rehnberg and S Ponte, "From Smiling to Smirking? 3D Printing, Upgrading and the Restructuring of Global Value Chains" (2018) 18 Global Networks 57.

8 I Gibson et al, Additive Manufacturing - 3D Printing, Rapid Prototyping, and Direct Digital Manufacturing (Springer 2014) 1-2.

9 For example, people can easily find a CAD file through platforms like Thingiverse. Such online platforms are mostly open-sourced, which means that a design might have been remixed several times before it is downloaded by a user. For more information, see < www.thingiverse.com/ > accessed 10 February 2019.

10 For the people who hold designs but not 3D printers, they can easily have the CAD file printed out by accessing printers through websites such as 3 DHubs. So far, more than 1.6 million products and components for various uses have been produced through 3DHubs since 2013: see <www.3dhubs.com/ > accessed 10 February 2019.
} 
contribution we will sketch out an institutional framework within which law and regulations could be further developed to guarantee socially desirable product safety standards, insofar as our article also contributes to the more general question of how a framework for digital governance might look.

\section{THE BLURRED PRODUCER-CONSUMER DIVIDE}

In incumbent liability regimes it is (rightly) assumed that there is a clear cut distinction between producers and sellers on the one hand and consumers on the other hand. ${ }^{11}$ Indeed, in traditional production regimes value is added along a linear supply chain, and a significant feature of linear supply chains is the division of producers and consumers. As a result we get clear cut roles along the value chain: Producers, sellers and consumers. They can all be separately identified.

Liability regimes typically target producers because they are the ones who profit mostly from business, who can pay out compensation and who - most importantly - are the ones who can make the product safer, with the help of research and development. ${ }^{12}$ Moreover, producers have typically a (large) production site which makes it possible to physically spot the issuer of a defective product and to enforce liability law and safety standards.

In the world of new digital technologies the distinction between producers and consumers is fading away. Some already speak of the prosumer as a new category. ${ }^{13}$ This makes it far more complicated to target the manufacturer of a defective product, which makes the incumbent tort law ultimately a blunt sword to reach optimal safety.

For example, a hobbyist software programmer may engage in co-drafting an opensource CAD file for 3D printing and share the code on a platform. ${ }^{14}$ Afterwards the hobbyist programmer uses the CAD file for 3D printing by herself, and others use the CAD file for commercial purposes. If the CAD file has a bug that leads to accidents, is it then the hobbyist programmer who can be held liable? Or, a hobbyist creator of 3D printed gadgets prints out replacement parts for an espresso machine. With those replacement parts he improves his espresso machine at home. But he also sells a couple of those parts via the internet. Unfortunately the sold parts let the coffee machines explode. Is the hobbyist printer who sold the parts via the internet liable according to product liability?

11 Recital 4 and Art 3 of Directive 85/374/EEC. See also K Oettmeier and E Hofmann, "Impact of Additive Manufacturing Technology Adoption on Supply Chain Management Processes and Components" (2016) 27(7) Journal of Manufacturing Technology Management 944; NF Engstrom, "3-D Printing and Product Liability: Identifying the Obstacles” (2013) 162 University of Pennsylvania Law Review Online 35.

12 AE Ackel, "Extending Liability to Micro-Manufacturers of the Future: Applying the CASUAL Seller Exception in the Context of 3-D Printing" (2018) 8 UC Irvine Law Review 121; see also Engstrom, supra, note 11.

13 The term "prosumer" was firstly coined by Alvin Toffler in 1980. It refers to the production activities that are undertaken by consumers: A Toffler, "The Rise of the Prosumer" (1980) The Third Wave 265. Meanwhile the meaning of the term has been broadened and indicates cases in which ordinary individuals are largely involved in peer productions: T Rayna and L Striukova, "Involving Consumers: The Role of Digital Technologies in Promoting 'Prosumption' and User Innovation" (2016) Journal of the Knowledge Economy 1.

14 P de Fillipi and P Troxler, "From Material Scarcity to Artificial Abundance: The Case of FabLabs and 3D Printing Technologies" in B van den Berg et al (eds), 3D Printing: Legal, Philosophical and Economic Diemensions (TMC Asser Press 2016) 65-83. 
In both cases it is questionable whether the hobbyist programmer and the hobbyist printer are strictly liable according to product liability, because they are also consumers and have no essential business or financial interest in the activity (besides the fact that the EU Product Liability Directive would not be applicable to software anyway). ${ }^{15}$ Nevertheless, the activity may unfold quite a large impact on business activities. An open source CAD file may become popular for 3D printing and may create widespread potential harm. One need only think about 3D printed LEGO bricks that injure children.

But even if one were of the opinion that the hobbyist 3D printers and CAD file creators can be made strictly liable under incumbent liability law by, for example, amending the EU Product Liability Directive, the two primary goals of liability law would not be accomplished: ${ }^{16}$ (1) typically hobbyist creators or producers do not have the funds to pay compensation to victims as companies do; (2) the deterrence of the liability regime will not and cannot incentivise the hobbyists to engage in systematic research and development, in order to improve product safety, as is the case with companies. Households have typically no research and development department. That means the two main reasons for the incumbent liability law no longer work, because the divide between consumers and producers is fading away in the realm of digitisation.

As a result, the blurred divide between producers and consumers leads to a situation in which it becomes even more important for the lawmaker to establish a regime of product liability that identifies causers of harm and can set proper incentives to bring damages on an optimal level. In the following sections we will identify more closely the disruption of the value chain as the main trigger for these problems.

\section{The CHALLENGE OF DISRUPTED VALUE CHAINS FOR LIABILITY}

New technologies are constituent for the Internet of Things, Smart Factory or Industry 4.0. The basic idea of these concepts is that manufacturing becomes self-organising, in the sense that all parts involved in manufacturing are communicating with each other, making it possible for tailor-made products to become available at low cost. ${ }^{17}$ The digital infrastructure becomes an enabler to import and export relevant data worldwide. In one country a smart algorithm produces a CAD file which is then directly sent to a $3 \mathrm{D}$ printer in another country, where the printed product can be sold instantly. ${ }^{18}$

\footnotetext{
15 According to Art 2 of the Directive 85/374/EEC, "products" only refer to "movable" ones. At the level of Member States, 18 Member States adopt the same concept of product in their acts that no extra-contractual protection is offered to the injuries and damages caused by intangibles and services. In contrast, nine Member States offered extra-contractual liability. In detail, seven of nine (Germany, Estonia, France, Malta, Netherlands, Slovenia and Slovakia) ensure a faultbased tort liability toward intangibles and services. The other two (Greece and Lithuania) stretch the notion of product to intangibles and services, so that intangibles and services are subject to strict product liability in those two Member States. The extent to which digital goods fall into the category of "movable products" is a controversial issue, which is not yet decided: Commission, "Evaluation of Council Directive 85/374/EEC on the approximation of laws, regulations and administrative provisions of the Member States concerning liability for defective products" (2018) 92.

16 Engstrom, supra, note 11.

17 M Brettel, "How Virtualization, Decentralization and Network Building Change the Manufacturing Landscape: An Industry 4.0 Perspective" (2014) 8(1) International Journal of Mechanical, Industrial Science and Engineering 37.

18 RE Baldwin, "Global Supply Chains: Why They Emerged, Why They Matter, and Where They are Going" (2012) CEPR Discussion Paper No DP9103.
} 
This example hints at a couple of legal challenges. With regard to liability regimes two issues have the foremost role: law enforcement and safety. The law enforcement problem originates because 3D print technology no longer needs a large production site to produce at low costs, and the product design, the digital CAD file, is independent from the place of printing. ${ }^{19}$ As a consequence small 3D printers may be located at remote places printing out exact copies of a CAD file that has been created at another remote place in the world. The remoteness of creation and production makes it inherently challenging to spot any kind of legal infringement and to enforce legal claims against CAD file creators or $3 \mathrm{D}$ printers. ${ }^{20}$ It becomes nearly impossible to trace back to find the perpetrator of an accident and to claim compensation along the contractual relations between the single steps in the value chain. ${ }^{21}$

With regard to safety, the disruption of value chains creates further challenges for society. This is because digital files in combination with 3D printers no longer require the production of intermediate goods which can be physically controlled along the value chain. There are no longer specialised (and maybe certified) sellers of intermediary goods, or retailers which may even have an obligation to insure their business. ${ }^{22}$ Instead a CAD file may go directly from an open source platform to a household that has access to a $3 \mathrm{D}$ printer without any contractual formalisation. ${ }^{23}$ More extremely, 3D printing circumvents explicit safety measures, as for example border controls in a harbour. A CAD file can directly go to a 3D printer at a remote place where innocuous raw material becomes transformed into a weapon. This reduces considerably the possibilities for authorities to control or prevent the manufacture of weapons and other hazardous products. ${ }^{24}$

Beyond the mentioned liability and safety issues there are other challenges which underscore the disruptive effect of $3 \mathrm{D}$ printing on traditional value chains. One of those challenges is that having less - or even no - intermediate goods in manufacturing implies that there is also less need for shipping (intermediate) products. ${ }^{25}$ As a consequence harbours will possibly play a smaller role for the transhipment of (intermediate) products. At the same time the shipping of raw materials for feeding 3D printers will become more important. ${ }^{26}$ In addition, governments are making revenue by imposing value added tax (VAT) and tariffs on goods, corresponding to the added value of each step in the value chain. But in case of 3D printing it is no longer clear when and where the

\footnotetext{
19 A Harris, "The Effects of In-home 3D Printing on Product Liability Law" (2015) 6(1) Journal of Science Policy and Governance.

20 ibid.

21 ibid.

22 C Twigg-Flesner, "Disruptive Technology - Disrupted Law? How the digital revolution affects (Contract) law" in A de Franceschi, European Contract Law and the Digital Single Market (Intersentia 2016).

23 C Twigg-Flesner, "Conformity of 3D prints - Can current Sales Law cope?" in R Schulze and D Staudenmayer (eds), Digital Revolution: Challenges for Contract Law in Practice (Nomos/Hart 2016).

24 In 2013, a CAD file for printing the plastic handgun was available online, which led to the debate on the regulation of 3D printing around the world. See DR Desai and GN Magliocca, "Patents, Meet Napster: 3D Printing and the Digitization of Things" (2013) 102 Georgetown Law Journal 1691.

25 B Berman, "3-D printing: The new industrial revolution" (2012) 55 Business Horizons 155.

26 D Bak, "Rapid Prototyping or Rapid Production? 3D Printing Processes Move Industry towards the Latter" (2003) 23(4) Assembly Automation 340.
} 
taxable added value has been created. ${ }^{27}$ Is it the creation of the CAD file (in one country) or is it the $3 \mathrm{D}$ printout (in another country) that creates value and accordingly the tax base? If the creation of the CAD file and the 3D printout belong separately to two countries, it is by no means clear to which country the revenue from VAT or tariffs belongs and how value creation can be metered. In any case the disruption of value chains through $3 \mathrm{D}$ printing will make it necessary to come up with new tax revenue sharing rules between countries.

\section{SAFETy, LiABILITY AND THE INFORMATION CONTEXT OF PRODUCTION SYSTEMS}

In the foregoing sections we pointed to two disruptive features of $3 \mathrm{D}$ printing which make it difficult to apply the traditional mode of liability rules to 3D printing as well as to maintain the incumbent economic rationality behind the design of liability rules. Thereby the disruption stems from the blurred distinction between producers and consumers on the one hand and from the disbanding of traditional value chains on the other hand.

In this section we will dig deeper into the underlying causes why the application of traditional liability rules in case of 3D printing cannot achieve the two goals of liability regimes: fair compensation and optimal deterrence. It will be shown that this is due to the informational scarcity of 3D printing which makes it very difficult to spot the causer of an accident as well as to set optimal incentives for preventing failures.

\section{The disclosure of safety information under modern mass production}

Economies of scale are key to competitive advantage in domestic as well as in international trade. ${ }^{28}$ Spreading fixed costs and reducing variable costs by expanding the production scale allows the average costs of production to be brought down and thus to make production processes more profitable. This is standard economic wisdom since Adam Smith's famous pin factory example. ${ }^{29}$ To be sure, in reality the realisation of economies of scale depends on the concrete case, and also the associated market structures that materialise on a continuum between perfect competition on the one hand and the natural monopoly on the other hand. ${ }^{30}$

Yet, what is important here is that over the whole continuum of market structures the same economic logic applies: it pays for the manufacturer to bring costs down according to economies of scale. In terms of industrial organisation the model of perfect competition describes then a competitive market in which firms are distinguished from each other according to their ability to bring down marginal costs compared to the socalled marginal producer, which makes no profit anymore (see Figure 1). At the other end of the continuum, the natural monopoly describes a situation in which only one firm

\footnotetext{
27 S Yanisky-Ravid and KS Kwan, "3D Printing the Road Ahead: The Digitization of Products When Public Safety Meets Intellectual Property Rights-A New Model” (2017) 38 Cardozo Law Review 921.

28 AO Laplume et al, "Global Value Chains from a 3D Printing Perspective" (2016) 47(5) Journal of International Business Studies 595.

29 LA Rivera-Batiz and PM Romer, "Economic Integration and Endogenous Growth" (1991) Quarterly Journal of Economics 531.

30 DW Carlton and JM Perloff, Modern Industrial Organization (4th edn, Pearson 2004).
} 


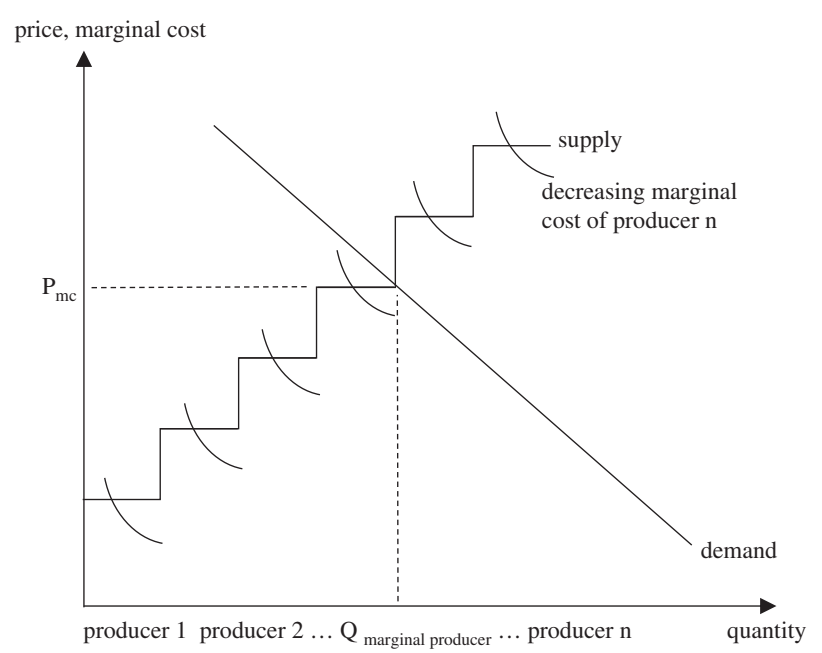

Figure 1. Marginal cost step function under perfect competition

can provide the product at the lowest cost level (see Figure 2). The natural monopolist is highly visible within the economic landscape and is typically the target of all kinds of regulatory measures to prevent a distortion of social welfare (see for example the regulation of public utilities with grid infrastructures).

Under perfect competition as well as in case of natural monopoly a linear value chain is established. Bulk orders received from downstream distributors and retailers make it profitable to reap the benefits from economies of scale. ${ }^{31}$

A linear value chain implies two important characteristics which are necessary for the workability of incumbent liability law. The first is that the product design, or the basic idea of the product, is closely related to the firm that manufactures and/or distributes the product. The product idea is the scarce resource that drives the firm's success on the market; it creates the firm's brand and largely determines the firm's value as well as the firm's strategy. ${ }^{32}$ The close relation between the product design and the manufacturing of the product in one firm within the nexus of contracts provided by company law allows the identification of the producer/seller of a specific defective product. The second characteristic is that value chains are established through vertical contracts. For example, a firm receiving a bulk order from downstream retailers will negotiate a better price from upstream input material vendors and may employ more advanced machines to enjoy the benefits from economies of scale. Hence the assembly of the product in a firm under a brand name creates a web of upstream and downstream contracts that allows the pinpointing of a potential trigger of a product failure vis-á-vis the user or consumer of the product. This way, under incumbent liability law, upstream cascades of liability build up, which unfold the right amount of deterrence against producers and sellers bringing defect products to the market.

31 IJ Petrick and WS Timothy, "3D Printing Disrupts Manufacturing: How Economies of One Create New Rules of Competition” (2013) 56 Research-Technology Management 12.

32 N Stieglitz and K Heine, "Innovations and the Role of Complementarities in a Strategic Theory of the Firm" (2007) 28(1) Strategic Management Journal 1. 


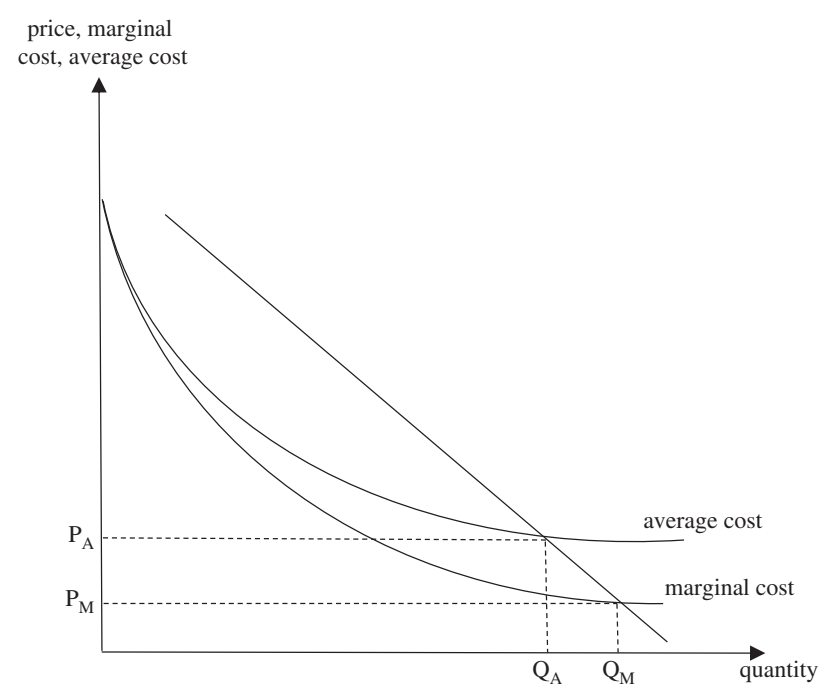

Figure 2. Natural monopoly

\section{Scarcity and information - the proper scope of traditional liability law}

Going analytically a step further, it is the information richness of traditional manufacturing (linear value chains) which makes it possible to detect a specific wrongdoer and at the same time to incentivise the prevention of product failure. Since it is typically firms that produce and sell products, there are legal entities in play that have the means to prevent defective products by systematic research and development. In addition, firms have the capacity to pay out compensation by contracting with appropriate insurance companies and to diversify the risk by producing different products. ${ }^{33}$

Thus the information needed to spot a wrongdoer and to achieve deterrence through liability law stems from the traditional way of organising production, ie the organisation of production in (large) firms to reap the benefits of economies of scale.

This is not saying that there are not all kinds of informational asymmetries around that can hinder (intermediate) producers or consumers from making efficient decisions. However, it can be expected that competition between producers in combination with smart regulations will ultimately pull out products that are on an efficient safety level.

More concretely, for the background of linear value chains a proper legal logic has unfolded, which efficiently allocates risks and responsibilities along the value chain. Here only some basic features of this logic are described, to make the differences clear when compared to a world of 3D printing.

The regime of product liability distinguishes between two generic features: (1) contracted damages; and (2) non-contracted damages. With regard to contracted damages, sales contracts play an important role in combination with product warranties. A possible damage is then compensated to the extent that the warranty foresees. Since those sales contracts are voluntarily signed, they are in the interest of the seller and buyer

33 RL Rabin, "Some Thoughts on the Ideology of Enterprise Liability” (1996) 55 Maryland Law Review 1190. 
and therefore efficient. ${ }^{34}$ However, sales contracts are insufficient to bring safety to an optimal level in cases where informational asymmetries are present or bargaining is impossible. ${ }^{35}$ In the latter case the damage is not contracted and is involuntary. For example, a defective car may injure pedestrians, who are not contracted to the car driver or to the manufacturer of the car. The car driver has driven correctly and was not aware that the car was defectively manufactured. In such cases, tort liability is expected to improve product safety, because it makes the manufacturer liable for having sold the defective product. Tort liability imposes the obligation to compensate victims that are not contracted to the tortfeasor. Other (more complex) cases of non-contracted damages can be construed, where a keen eye along the linear value chain helps to determine which party shall be held liable to bring the care level and the activity level of the involved parties as close as possible to economic optimality.

This logic has also been applied by the EU to a large extent. Since the 1960s, with the establishment of the common market, strict product liability has been gradually introduced in Europe to achieve a level playing field between European manufacturers and to reap the benefits of mass production and competition in a common market. ${ }^{36}$ In 1985, the European Product Liability Directive (EPLD) formally established strict product liability in the EU. ${ }^{37}$ The economic rationale behind the introduction of strict liability is that (on average) it supports the goal of efficiency better than other liability rules. ${ }^{38}$

While negligence liability puts the residual liability on consumers, strict liability puts it on the manufacturers. The determination of which party is better suited to be the residual liability bearer depends on who can avoid the accident at the cheapest cost. ${ }^{39}$ Since economies of scale determine largely economic success, firms are regarded as the cheapest cost avoider. ${ }^{40}$ Firms have the expertise as well as advanced machinery to detect and avoid product failures. Moreover, firms control distribution channels and can thus stop the proliferation of defective products. ${ }^{41}$ Finally, compared to consumers firms have a deeper pocket and diverse means of (self-)insurance to bear financial loss. ${ }^{42}$ Therefore, it is reasonable to impose residual liability on manufacturers, and to incentivise them in this way to take the necessary precautions against defective products.

\footnotetext{
34 SJ Grossman, "The Informational Role of Warranties and Private Disclosure about Product Quality" (1981) 24(3) Journal of Law and Economics 461; GL Priest, "A Theory of the Consumer Product Warranty" (1981) 90(6) Yale Law Journal 1297.

35 AL Wickelgren, "The Inefficiency of Contractually-Based Liability with Rational Consumers" (2005) 22(1) Journal of Law, Economics, and Organization 168; see also AH Choi and KE Spier, "Should Consumers be Permitted to Waive Products Liability? Product Safety, Private Contracts, and Adverse Selection” (2014) 30(4) Journal of Law, Economics, and Organization 734.

36 For an overview of the legislative process across the Europe, see Whincup, supra, note 4; Howells, supra, note 4.

37 Directive 85/374/EEC, supra, note 5.

38 J Arlen, "Economic Analysis of Tort Liability for an Imperfect World" in F Parisi (ed), The Oxford Handbook of Law and Economics (Oxford University Press 2017).

39 Calabresi, supra, note $1,139$.

40 GL Priest, "The Invention of Enterprise Liability: A Critical History of the Intellectual Foundations of Modern Tort Law" (1985) 14(3) Journal of Legal Studies 461.

41 Harris, supra, note 19.

42 GL Priest, "The Modern Expansion of Tort Liability: Its Sources, Its Effects, and Its Reform" (1991) 5(3) Journal of Economic Perspectives 31; see also Calabresi, supra, note 1, 40.
} 
Imposing strict liability on producers also supports the proper identification of product risks by consumers when the product quality cannot fully be assessed. In a competitive market the product price is considered as an important signal to estimate the risk of the product. ${ }^{43}$ Assuming that consumers have at least some knowledge about the product that they intend to buy, then they can trace back from the price the likely precautions undertaken by the manufacturer as well as the expected harm in case of an accident. But even where consumers cannot correlate the product quality with the price level, strict liability sets the most appropriate incentives for the producer to undertake precautionary measures. ${ }^{44}$ That is simply because under strict liability the manufacturer bears the loss whenever an accident occurs. Hence producers will strive to minimise accident costs by targeting the optimal care level as well as activity level. Therefore, even if consumers misperceive the risk of a product through a lack of information, on average they can make proper choices according to market prices. ${ }^{45}$

Besides the (ex post) threat of being held liable in a law suit, specific safety regulations can be employed in order to determine (ex ante) the quality standard of a product. A certain product may only be sold if it fulfils the requirements set by a governmental agency. This is the case, for example, with pharmaceuticals, but also certain professional services may only be offered by certified persons and agencies.

At first glance the setting of specific regulations for product qualities and quantities seems to be an easy way to control product risks. But that is not the case. Quite often it is not clear what the efficient regulation would be, and typically no room is left to deviate to cheaper regulations, ultimately ignoring the diverse preferences of consumers. Moreover, producers and lobby groups may have a strong interest in pressuring the regulator to come forth with specific regulations that pay for them but not for their competitors and/or consumers. Finally, a strong organisation and proper processes are needed to enforce safety regulations. In this regard in recent years the EU has empowered its institutions and in 2008 came up with a particular mechanism called the "New Legislative Framework", which diminishes the information problem between producers and consumers as well as authorities. ${ }^{46}$ Within this framework market surveillance is centre stage. It comprises a close monitoring of supply chains and the distribution of products to consumers. Whenever an unsafe product is identified,

\footnotetext{
43 AF Daughety and FR Jennifer, "Economic analysis of products liability: theory" in Jennifer Arlen (ed), Research Handbook on the Economics of Torts (Edward Elgar 2013) 69-96.

44 S Shavell, Foundations of Economic Analysis of Law (Harvard University Press 2004) 221.

45 M Spence, "Consumer Misperceptions, Product Failure and Producer Liability" (1977) 44(3) The Review of Economic Studies 561; AM Polinsky, "Strict Liability vs. Negligence in a Market Setting" (1980) 70(2) The American Economic Review 363; MA Geistfeld, "Products Liability" in M Faure (ed), Tort Law and Economics (Edward Elgar 2009).

46 The New Legislative Framework consists of three pillars: Regulation (EC) No 765/2008 of the European Parliament and of the Council of 9 July 2008 setting out the requirements for accreditation and market surveillance relating to the marketing of products and repealing Regulation (EEC) No 339/93 [2008] OJ L 218; Decision No 768/2008/EC of the European Parliament and of the Council of 9 July 2008 on a common framework for the marketing of products, and repealing Council Decision 93/465/EEC [2008] OJ L 218; and Regulation (EC) No 764/2008 of the European Parliament and of the Council of 9 July 2008 laying down procedures relating to the application of certain national technical rules to products lawfully marketed in another Member State and repealing Decision No 3052/95/EC [2008] OJ L 218. Aligned with these, a bundle of directives and regulations in specific sectors are also promulgated. Under this framework a wide array of regulatory instruments, ranging from market surveillance rules to particular conformity assessments, are provided to ensure producers place safe products in the common market.
} 
withdrawals and recalls will be enforced to put relevant products out of the market. ${ }^{47}$ In order to ensure information is exchanged rapidly among different authorities, specific regimes like $\mathrm{ICSMS}^{48}$ and $\mathrm{RAPEX}^{49}$ have been established. In addition, the EU prescribes a couple of information disclosure mechanisms for producers and sellers. A well-known quality label is, for example, the CE certification mark, which states that the product conforms to actual product regulations. ${ }^{50}$

What is important here is that according to the linear value chains of production a complementary regime of laws and regulations has emerged that facilitates not only the market transactions between producers and consumers but also supports the differentiation and specialisation within value chains and the reaping of economies of scale. It does not need much imagination to envisage the disruptive forces on the legal framework if the traditional mode of production within linear value chains collapses. In the event that economies of scale play less of a role for production, then the informational content associated with a specific stage of production will decrease and the applicability of incumbent liability law and safety regulations will become much harder to establish, if not impossible.

\section{The end of scarcity and the informational deficits in a world of 3D printing}

Different from traditional manufacturing, value creation in $3 \mathrm{D}$ printing is not driven by economies of scale. ${ }^{51}$ One author even speaks vividly about a "World without Scarcity", when a digital design can be used at any place in the world at the same costs for any quantity of production. $^{52}$

More specifically, using 3D printing technology means that the same amount of raw material is always consumed at the same cost level of combined production factors, whereby the combination of production factors is mainly the $3 \mathrm{D}$ printer itself. ${ }^{53}$ Hence, if there is any cost reduction in the production process then it is because of lower prices for raw material, a better printer technology or a better digital design (incorporated in the CAD file). Input costs are not unique for a specific company engaged in 3D printing, but industry wide are more or less the same. Also entrepreneurial spirit plays only a minor role when the CAD file and a given printer technology exclusively determine the final product. $^{54}$ In addition, variants of the basic product can easily be printed out without

47 Art 30 of Regulation (EC) 765/2008.

48 ICSMS serves as a networking system through which surveillance authorities are able to exchange information. By doing so, information can be exchanged among various surveillance bodies in a fast and transparent way. The details are available at $<$ webgate.ec.europa.eu/icsms $/>$.

49 RAPEX refers to the "rapid alert system" across the EU. Under this system, if a manufacturer finds its products are not safe, it has to withdraw and recall these products and notify the national authorities. The national authorities will then notify the EU, who will swiftly report this issue online. See Arts 11-13, Directive 2001/95/EC of the European Parliament and of the Council of 3 December 2001 on general product safety [2001] OJ L11.

50 The requirement of CE marking is specifically determined by the bundle of directives under the "New Legislative Framework". For guidance on the implementation of CE marking, see Commission, "The 'Blue Guide' on the Implementation of EU Product Rules" 2016/C 272/01.

51 Petrick and Timothy, supra, note 31.

52 MA Lemley, "IP in a World without Scarcity" (2015) 90 New York University Law Review 460.

53 Berman, supra, note 25.

54 J Maric et al, "Frugal innovations and 3D printing: insights from the field" (2016) 3 Journal of Innovation Economics \& Management 57. 
incurring much extra cost. In this regard value is created not by expanding the production scale to get cheaper products, but through producing a more heterogeneous set of products at the same cost level. Thus, with the help of 3D printing, demand from the niche market - no matter how small it is - can be served. ${ }^{55}$

Since in 3D printing economies of scale no longer play a role for capturing value, factors like the lack of advanced machinery, the absence of an effective organisational firm structure or a lack of bargaining power are no longer barriers for a new producer to enter the market. ${ }^{56}$ Also the market exit costs are low when it is easy to react to shifts in demand. Therefore more market entries are possible and actual and potential competition is high. In addition, as mentioned before, the distinction between consumers and producers is blurred when 3D printers become available for households or if hobbyists can co-create CAD files.

As a result 3D printing has broken up linear value chains and has replaced it with a more decentralised or multicentred web of value creation. ${ }^{57}$ This is mainly because of the decoupling of (digital) design from manufacturing, in which independent designers substantially contribute to the final product by providing the product idea. ${ }^{58}$ On the other hand, due to the low market entry threshold, individuals or firms with or without knowledge of manufacturing can engage in designing or manufacturing 3D printed products. The organisation of the activities works via online platforms, replacing a linear value chain with a decentralised web of value creation. Value is created by serving heterogeneous demands instead of bringing down costs by economies of scale. ${ }^{59}$

In summary, in 3D printing: (1) the product design is decoupled from manufacturing; (2) the production process becomes highly standardised; (3) the distinction between producer and consumer is blurred; and (4) the organisation of the activities takes place at online platforms. As a result the information needed to trace the source of a defective 3D printed product becomes very difficult to find. In other words, 3D printing produces only light or no footprints at all, which makes it demanding to identify a culprit in case of harm, damage or wrongdoing.

The technical conditions under which 3D printing takes place translate economically into an extreme form of perfect competition in which it is not possible to distinguish between the atomistic suppliers, because all firms produce at the same marginal cost level. In addition, it is not always possible to separate consumers from producers. The market participants can take over both roles simultaneously or switch between them easily.

The replacement of linear value chains by value creating webs of design and manufacturing in combination with the irrelevancy of economies of scale has a

\footnotetext{
55 T Rayna and L Striukova, "From Rapid Prototyping to Home Fabrication: How 3D Printing is Changing Business Model Innovation" (2016) 102 Technological Forecasting and Social Change 214.

56 C Weller, "Economic Implications of 3D Printing: Market Structure Models in light of Additive Manufacturing Revisited" (2015) 164 International Journal of Production Economics 43.

57 A Ben-Ner and E Siemsen, "Decentralization and Localization of Production: The Organizational and Economic Consequences of Additive Manufacturing (3D Printing)” (2017) 59(2) California Management Review 5.

58 M Bogers et al, "Additive Manufacturing for Consumer-Centric Business Models: Implications for Supply Chains in Consumer Goods Manufacturing” (2016) 102 Technological Forecasting and Social Change 225.

59 Petrick and Timothy, supra, note 31.
} 
disruptive effect not only on incumbent production processes but also on the incumbent legal frameworks guiding and facilitating manufacturing and trading.

The scarcity of information about identifying the source or cause of a defective product increases misperceptions by consumers and public authorities when they try to adapt to the potential risks associated with a 3D printed product. Additionally, informational scarcity makes it challenging to target liability rules at those who could efficiently prevent damages. In other words, the incentive logic of traditional tort law begins to falter.

\section{LEGAL DISRUPTIONS AND THE WAY AHEAD}

In this section we will highlight the legal disruptions which are triggered by 3D printing technology. Our focus will be on liability law and safety regulation. But it is clear that also other legal areas are impacted by this new technology. Intellectual property rights, especially, are challenged when it becomes possible that identical copies of a product can be printed out at remote places. ${ }^{60}$ This leads to the quite fundamental question, asking under which circumstances it may make sense to protect copyrights, patents and trademarks at all, because maintaining high legal fences against infringers becomes very costly for society when digitalisation conquers more and more fields in which human creativity plays a decisive role. Would it not be smarter to employ other means than property rights to compensate inventors?

\section{A rugged legal landscape: scale, organisation and contract}

If there are economies of scale in production then this has a quite huge effect on the application of law. More precisely, the more economies of scale that are exploited in a production process, the bigger the production site has to become. This typically goes hand in hand with a higher degree of division of labour and more elaborate organisational firm structures reflected in company law. This makes it easy to distinguish between producers and consumers.

For law enforcement it means that the producer of a defective good is physically visible. There is a production site that can be spotted on a map. Even though the production might be at a remote place in the world it can be located and, if necessary, prosecuted. There might well be intriguing international law problems involved in enforcing a legal title, but this is more of a practical problem than one of principle.

In a world of $3 \mathrm{D}$ printing law enforcement becomes challenged. The production of a defective product is no longer associated to a physically visible production site. ${ }^{61}$ To make an extreme case: a household at a remote place prints out a considerable number of weapons. This dangerous activity is close to invisible and enforcing a stop of production may take a while, even though there might be international consent to stop the proliferation of 3D printed weapons. A different case, but with similar effect, emerges

\footnotetext{
60 For the literature on 3D printing and intellectual property law, see D Doherty, "Downloading Infringement: Patent Law as a Roadblock to the 3D Printing Revolution" (2012) 26 Harvard Journal of Law and Technology 353; see also B Depoorter, "Intellectual Property Infringements \& 3D Printing: Decentralized Piracy" (2013) 65 Hastings Law Journal 1483.

61 Harris, supra, note 19.
} 
when the trigger of the defective product is a failure in the program code of the CAD file that has been downloaded from a platform anonymously a thousand times. Independently from the question of what the responsibilities of the platform here might be, it can become very challenging to trace the programmer(s) of the defective code (this is even more a problem if it is an open source code). ${ }^{62}$

Traditionally the very idea of a product determines the success of a firm. It is not necessary that the product design and manufacturing are vertically integrated in one company, and other contractual relations are possible. ${ }^{63}$ But the strategic direction of the value-creation process of the product is in one hand, in order to accrue the profit for the inventor. ${ }^{64}$ As a result, it is reasonable to target firms with strict liability and to expect that firms become optimally deterred from selling defective products, meaning they will bear prevention costs on a socially efficient level. ${ }^{65}$ Firms thus have an incentive to invest in research and development and to come up with safer products.

3D printing breaks up the strategic unity of product design and manufacturing. 3D printing leads to the decoupling of product design and manufacturing, implying that the assignment of liability - as in linear value chains - is no longer possible. ${ }^{66} \mathrm{~A} 3 \mathrm{D}$ printing company as well as a hobbyist 3D printer download an appropriate CAD file from a platform. The CAD file can then be adapted or manipulated to the specific needs of the user. The users may have very different capabilities, resources and inclinations to do those manipulations competently. ${ }^{67}$

Unlike risk management under a unitary organisational structure and central strategic direction, a manufacturer of 3D printed products has to take extra efforts to discern the potential risks embedded in the product design. It is questionable whether a manufacturer of $3 \mathrm{D}$ printed products will bear those costs.

The CAD file typically comes from a platform which functions as an intermediary for the distribution of the CAD file. The platform does not work as a monitor or guarantor of the quality of the CAD file. That means that even if liability law were targeted at the manufacturer of the 3D printed product, it would not trigger the incumbent logic. A hobbyist printer typically does not have the technological expertise to assess the risk inherent to a specific CAD file. Neither does he or she have the means to run a research and development department to calibrate prevention costs with the potential profits of an improved product. Moreover, individuals and companies can hardly convey the need for improving a CAD file to a platform where very diverse contributors of CAD files meet (anonymously) with each other. To put it differently: an internet platform is an intermediary, and not a sort of research and development department that works under the strategic direction of a boss who has a specific entrepreneurial product idea. For that

\footnotetext{
62 Harris, supra, note 19.

63 K Heine and M Kerk, "Conflict Resolution in Meta-organizations: the Peculiar Role of Arbitration" (2017) 6(1) Journal of Organizational Design 3.

64 Stieglitz and Heine, supra, note 32.

65 JC Goldberg and BC Zipursky, "The Easy Case for Products Liability Law: A Response to Professors Polinsky and Shavell” (2010) 123(8) Harvard Law Review 1919.

66 A Marucheck et al, "Product Safety and Security in the Global Supply Chain: Issues, Challenges and Research Opportunities" (2011) 29(7-8) Journal of Operations Management 707.

67 JM Beck and MD Jacobson, "3D Printing: What Could Happen to Products Liability When Users (and Everyone Else in between) Become Manufacturers” (2017) 18 Minnesota Journal of Law, Science \& Technology 143.
} 
background it is worthwhile for future research to further explore the role of platforms and to elaborate on their legal design, which possibly should go beyond that of a pure intermediary.

Hierarchy within an organisation is one possibility by which to direct production processes; using the market and contracts is another, to give strategic direction to production processes. In a world of 3D printing contracts do not disappear, but they do not play a central role for the organisation of production. Hence contracts have only a small impact for the control of risks. ${ }^{68}$ Again, this has to do with the decentralised value creation organised via platforms.

Product designs are not developed in specialised research and development centres of firms but put on online platforms for download and possible further improvement, regardless of their origin (households, firms, universities etc). From those platforms users retrieve (anonymously) the CAD file without specifying in a contract what the specific obligations of the user and the platform are. Furthermore, there might be no contractual relationship between the CAD file designers and the manufacturers. Designers place the CAD file online by registration, without substantive review from the platform. The user will only get a safety warning or specification by coincidence, and this information may come from a different source than the platform. For that background the contractual relationship - if there is one at all - becomes empty and it is not a suitable means to tackle product safety issues. As a result platforms claim to be a marketplace for supply and demand but not a contractor and they deny any responsibilities for potential harm. Only where a platform knows or becomes informed that a harmful 3D print design is exchanged on the platform does it have to take steps and remove it according to EU law. ${ }^{69}$

Without sequential contractual relationships along the supply chain 3D printing exposes end-consumers or end-users to large risks. On the one hand online platforms have no incentive to acquire information about product risks from designers and manufacturers, because yet they are not contracted to their customers. ${ }^{70}$ On the other hand, without a formal contractual relationship instituting certain liabilities the identification of specific designers and manufacturers becomes nearly impossible. ${ }^{71}$ Admittedly, online platforms bring designers, manufacturers and consumers directly into contact and they may have the chance to identify each other. However, without sequential contracting in a linear supply chain the risk allocation remains doubtful and the deterrent provided by tort law becomes blunt, especially in a cross-border setting. Future research may come up with proposals for how to rectify the contractual deficits associated to online platforms for CAD files, but for the moment safety issues cannot be tackled within contracts. ${ }^{72}$

\footnotetext{
68 PJ Comerford and EP Belt, "3DP, AM, 3DS and Product Liability” (2015) 55 Santa Clara Law Review 821.

69 Art 14 of the Directive 2000/31/EC of the European Parliament and of the Council of 8 June 2000 on certain legal aspects of information society services, in particular electronic commerce, in the Internal Market (Directive on electronic commerce) [2000] OJ L 178.

70 Twigg-Flesner, supra, note 23.

71 Harris, supra, note 19.

72 A couple of ideas of how a liability regime for online platforms might look have been presented. See A de Streel et al, "Liability of internet platforms: should exceptionalism end?" (2018) CERRE Report; see also O Lobel, "The Law of the Platform" (2016) 101 Minnesota Law Review 87.
} 
The shifts in scale, organisation and contracts leave us with a rugged legal landscape. $3 \mathrm{D}$ printing has not only a disruptive effect on the incumbent legal routines which guarantee fair compensation for victims, it also fails to fit into the tort law logic where strict liability of producers leads to optimal deterrence of harmful products. Therefore it comes as no surprise that in summer 2018 the European Commission formed an expert group (Expert Group on Liability and new technologies) to assess the disruptive impact of new technologies on liability issues. ${ }^{73}$ The aim of this expert group is to come up with ideas on how a new product liability directive might look, which take into account the legal disruptions triggered by new technologies. ${ }^{74}$

\section{The institutional framework for finding new legal solutions - digital governance}

In this article we have identified the technological and economic drivers of 3D printing and their impact on liability law. We could show that the application of incumbent liability regimes to $3 \mathrm{D}$ printing becomes a tedious exercise. No one can tell at the moment how future laws and regulations must be structured in order to lift the full economic potential of 3D printing and to guarantee optimal safety for users and consumers at the same time. But what we do know is that the identified drivers are a sort of game changer; we can no longer take for granted that incumbent liability law and safety regulations induce the optimal level of precautions, nor that (fair) compensation to victims can be paid.

The main reason for the misfit between incumbent liability law and 3D printing is the lack of economies of scale which leads to a high degree of technological homogeneity between the products as well as the producers of 3D printed products, in combination with possibly small and scattered producers. The consequence is a lack of information for separating horizontally and vertically between tortfeasors along the value chain. However, the legal system needs exactly this specific information in order to target incentives for deterrence (obligation to pay compensation) at potential causers of harm. Moreover, the separation problem is amplified by online platforms which cut through the contractual relations between CAD file designers and producers. As a result, the incentive logic of incumbent tort law collapses. One can express this even more pointedly: the application of incumbent liability law will lead to improper risks for consumers and/or hindrances for the economy in exploiting the full potential of 3D printing.

Because even looking into a crystal ball will hardly help us to find appropriate laws and regulations for guiding the growing economic importance of $3 \mathrm{D}$ printing, in the remainder of this article we will briefly sketch out which institutions have to be brought into play to find proper legal frameworks for 3D printing. Hence, a few words about digital governance will conclude the article.

\footnotetext{
73 For details, see < ec.europa.eu/transparency/regexpert/index.cfm?do=groupDetail.groupDetail\&groupID=3592 >.

74 In 2016 the Commission started an evaluation of the EPLD to examine whether it is still efficient in the era where disruptive technologies are widely adopted. The final report was released in May 2018, supra, note 15.
} 
3D printing and other new technologies, for example robotics and artificial intelligence, not only have an impact on the design of national liability law and safety regulations, or on a possible new Product Liability Directive for the EU. The disruptive nature of digital technologies also gives rise to the question of which institutional setting is the most appropriate forum for a full exploitation of new technologies, such as 3D printing. Is there an appropriate digital governance structure for 3D printing and other new technologies?

The legislator is the political starting point for the design of any regulatory regime. The strength and importance of the legislator comes from its power to address new societal problems, to give them a value-laden debate and finally to give democratic legitimacy to new legal rules. Since any new liability regime needs anchorage and acceptance in society, it is essential that any rule-setting takes place in accordance with the legislator. This is even more important because the legislator can forcefully trigger or stop initiatives. On the other hand, the legislator is often prey to interest groups and has a relative lack of technical competence. ${ }^{75}$

From this, it follows that at the level of the legislator two important things have to be managed in order to raise the likelihood that welfare-increasing laws and regulations are implemented. The first is that the legislator needs the support of (technical) experts, who can explain the ways in which a digital technology produces new risks, and how the technology will affect the incumbent legal setting. This kind of support is not easily achieved, because it is not sufficient to simply assemble engineers, economists, lawyers and other disciplines, all of whom look on the subject matter only from their own methodological and normative perspective. Instead a multi-disciplinary reflection about the chances and risks of digital technologies must be initiated. Moreover, the reflection must be comprehensible for the legislator. Otherwise it will not receive sufficient attention and the drafting of appropriate laws and regulations will be stalled. The second thing that must be managed is a societal discourse about digital technologies. In this discourse the various stakeholders and the electorate must have the opportunity to express their opinions about possible new legal designs. Entering into a sort of public discourse creates not only (extra) legitimacy, but it also serves as an early warning system for possible societal hindrances when the political process has reached the implementation stage of the new law or regulations. In other words, it helps to avoid the situation where, at a relatively late stage of the legislative process, political arguments come into play which thwart a new law that is in principle socially beneficial.

Other than the legislator, tailor-made regulatory agencies can be established for a specific purpose, for example for the regulation of robotics, artificial intelligence, 3D printing or combinations of new technologies. Those agencies are staffed with experts from the field, which are supposed to propose and monitor adequate design regulations for $3 \mathrm{D}$ printers. Or the agency analyses the algorithms with which CAD files are programmed. Thus, regulatory agencies are powerful tools to deal with the problems associated with specific technologies. However, they have a "permanent" lack of legitimacy, in the sense that they only gain legitimacy through the legislator who

75 MU Scherer, "Regulating Artificial Intelligence Systems: Risks, Challenges, Competencies, and Strategies" (2016) 29(2) Harvard Journal of Law \& Technology 376. 
constitutes the agency in a legal act. An agency cannot, by itself, ask the electorate for legitimacy.

A legislature typically fears losing control over agencies ("mission creep") and therefore it has a tendency to restrict their flexibility. In 3D printing and other new technologies, this leads to a trade-off: on the one hand any agency regulating a new technology needs a strong legitimacy, backed up by the legislature; on the other hand, there must be enough room for flexible regulation. A regulatory agency must react to technological dynamics and has to prevent a situation in which innovation and growth become stifled by improper and outmoded regulations. Thus, a liability regime for 3D printing must strive for sufficient regulatory openness on the one hand and legitimate control on the other hand. This goal might be better achieved by the formulation of relatively open regulatory standards than highly specific rules. ${ }^{76}$

While legislation and regulation have effect ex ante, courts come into play ex post, when harm has already occurred. Liability law has an ex ante deterrent effect, but a case can only be brought to court after the harm has occurred. The court focuses on the risks of a technology in a specific case, and whether due care has been taken by the involved parties. The broader societal aspects of a technology play no role in the court, and courts are also bound to the law and have only limited leeway to come up with new interpretations of the law, insofar as liability law is inherently conservative. This is not necessarily a failure, because judges are neither technology experts nor social engineers. It might even become dangerous to give them too much freedom, but in the case of 3D printing and new technologies, courts may stifle innovation to the detriment of society. Therefore it seems wise to design the liability law which is applicable for new technologies in such a way that the reactive measures taken by courts do not hinder the exploitation of these technologies for society. This includes the avoidance of wrong incentives for plaintiffs' lawyers who are out to get a "golden" settlement when new technologies enter the court room for the first time. Thus, the strategic behaviour of the courtroom should also be taken into account when new rules for new technologies are designed. ${ }^{77}$ It is, at the moment, by no means clear what a renewed liability law might look like, or how it might perform in specific cases, but it might be handy to have an obligation for the legislator to regularly review liability law. This would strengthen the relationship and exchange between courts and the legislator, and lead to the flexibility and improvements that are much needed by a liability law that has to deal with disruptive innovations.

\footnotetext{
6 ibid, p 381.

77 ibid, p 388.
} 